Document downloaded from:

http://hdl.handle.net/10251/121078

This paper must be cited as:

Crespo-Peremarch, P.; Ruiz Fernández, LA.; Balaguer-Beser, A.; Estornell Cremades, J. (2018). Analyzing the role of pulse density and voxelization parameters on full-waveform LiDAR-derived metrics. ISPRS Journal of Photogrammetry and Remote Sensing. 146:453464. https://doi.org/10.1016/j.isprsjprs.2018.10.012

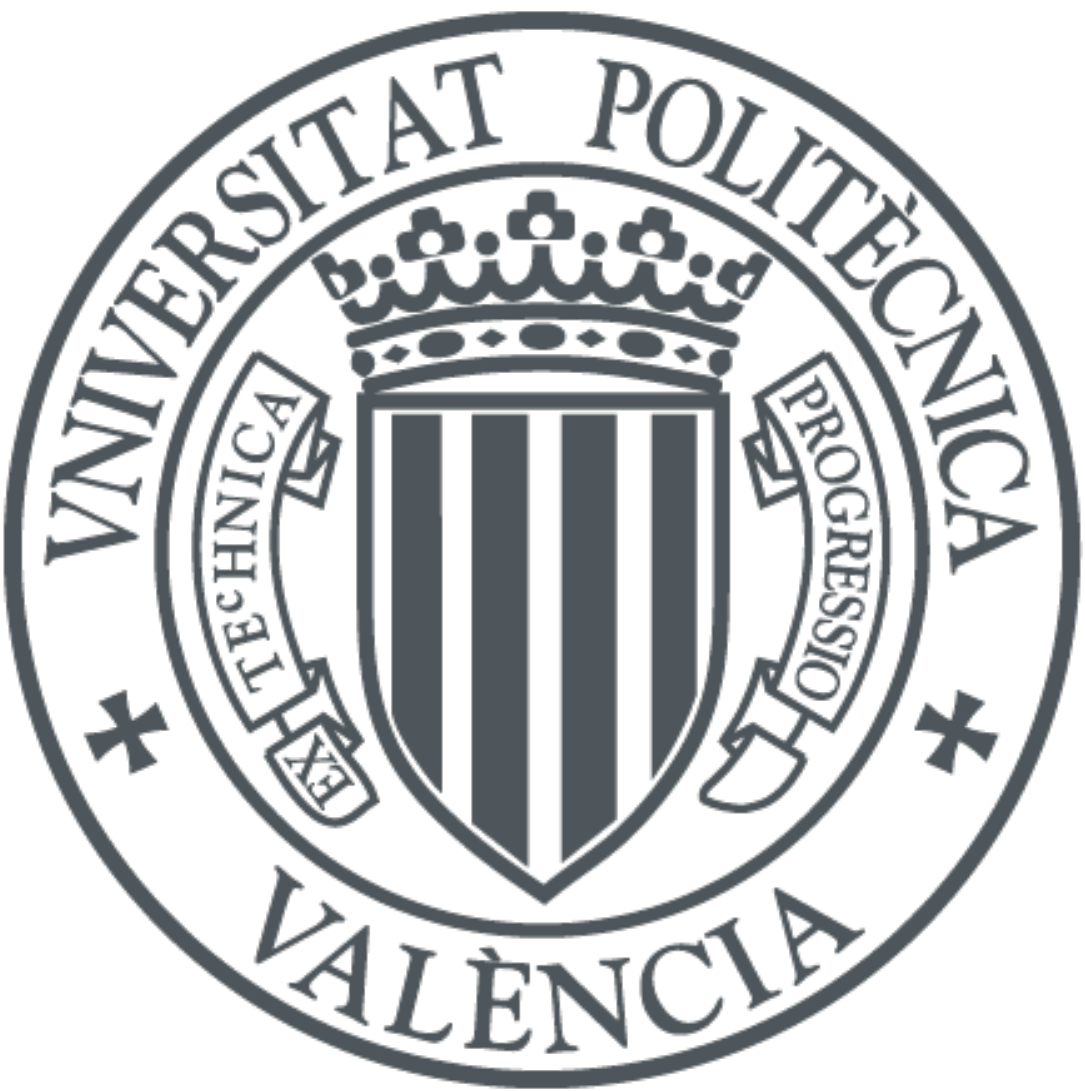

The final publication is available at

https://doi.org/10.1016/j.isprsjprs.2018.10.012

Copyright Elsevier

Additional Information 


\section{Analyzing the role of pulse density and voxelization parameters on}

\section{2 full-waveform LiDAR-derived metrics}

4 Crespo-Peremarch, Pablo ${ }^{1,2^{*}}$, Ruiz, Luis Ángel ${ }^{1,2}$, Balaguer-Beser, Ángel ${ }^{1,3}$ and Estornell, Javier ${ }^{1,2}$

$5 \quad{ }^{1}$ Geo-Environmental Cartography and Remote Sensing Group (CGAT), Universitat Politècnica de

6 València, Camí de Vera s/n, 46022, València, Spain.

$7 \quad{ }^{2}$ Department of Cartographic Engineering, Geodesy and Photogrammetry, Universitat Politècnica de

8 València, Camí de Vera s/n, 46022, València, Spain.

$9{ }^{3}$ Department of Applied Mathematics, Universitat Politècnica de València, Camí de Vera s/n, 46022, 10 València, Spain.

12 Keywords: airborne laser scanning, voxelization, voxel size, assignation value, side-lap effect.

14 Abstract

15 LiDAR full-waveform ( $\mathrm{LFW}_{\mathrm{FW}}$ ) pulse density is not homogeneous along study areas due to overlap 16 between contiguous flight stripes and, to a lesser extent, variations in height, velocity and 17 altitude of the platform. As a result, $\mathrm{LFW}_{\mathrm{FW}}$-derived metrics extracted at the same spot but at 18 different pulse densities differ, which is called "side-lap effect". Moreover, this effect is reflected 19 in forest stand estimates, since they are predicted from $\mathrm{L}_{\mathrm{FW}}$-derived metrics. This study was

\footnotetext{
${ }^{*}$ Corresponding author

Email address: pabcrepe@cgf.upv.es
} 
undertaken to analyze $\mathrm{L}_{\mathrm{FW}}$-derived metric variations according to pulse density, voxel size and

21 value assignation method in order to reduce the side-lap effect. Thirty LiDAR samples with a

22 minimum density of 16 pulses $\mathrm{m}^{-2}$ were selected from the testing area and randomly reduced to 2

23 pulses $\mathrm{m}^{-2}$ with an interval of 1 pulse $\mathrm{m}^{-2}$, then metrics were extracted and compared for each

24 sample and pulse density at different voxel sizes and assignation values. Results show that LFW- $_{\mathrm{FW}}$

25 derived metric variations as a function of pulse density follow a negative exponential model

26 similar to the exponential semivariogram curve, increasing sharply until they reach a certain

27 pulse density, where they become stable. This value represents the minimum pulse density

28 (MPD) in the study area to optimally minimize the side-lap effect. This effect can also be

29 reduced with pulse densities lower than the MPD modifying LFw parameters (i.e. voxel size and

30 assignation value). Results show that $\mathrm{L}_{\mathrm{FW}}$-derived metrics are not equally influenced by pulse

31 density, such as number of peaks (NP) and ROUGHness of the outermost canopy (ROUGH) that

32 may be discarded for further analyses at large voxel sizes, given that they are highly influenced

33 by pulse density. In addition, side-lap effect can be reduced by either increasing pulse density or

34 voxel size, or modifying the assignation value. In practice, this leads to a proper estimate of 35 forest stand variables using $\mathrm{L}_{\mathrm{FW}}$ data.

\section{Introduction}

LiDAR technologies have been widely used on forest applications during the last decades.

39 Discrete LiDAR $\left(\mathrm{L}_{\mathrm{D}}\right)$ is the most common LiDAR data. Its success for estimating forest stand

40 variables and classifying fuel models has been proven in several studies (Lim et al., 2003;

41 Bortolot and Wynne, 2005; Mutlu et al., 2008; Ruiz et al., 2018; Guerra-Hernández et al., 2016;

42 Hevia et al., 2016). LiDAR full-waveform ( $\left.\mathrm{L}_{\mathrm{FW}}\right)$ has also been used for estimating forest stand 
43 variables (Cao et al., 2014; Hermosilla et al., 2014a), classifying tree species (Reitberger et al.,

44 2008; Heinzel and Koch, 2011; Cao et al., 2016) and segmenting single trees (Reitberger et al.,

45 2009). LFw registers the complete signal emitted from the system and backscattered from

46 different vertical layers (Mallet and Bretar, 2009). The amplitude of the waveform in each bin is

47 related to the physical properties of the object reached (Song et al., 2002; Guo et al., 2011;

48 Hermosilla et al., 2014a) and to the angle of incidence (Kukko et al., 2008). Therefore, compared

49 to the $L_{D}$, it provides more information about the vertical distribution of the vegetation.

50 However, $\mathrm{L}_{\mathrm{FW}}$ processing is more complex and time consuming, so it has been used much less

51 frequently than $\mathrm{L}_{\mathrm{D}}$.

52

53 Both $\mathrm{L}_{\mathrm{D}}$ and $\mathrm{LFW}_{\mathrm{FW}}$ usually present heterogeneous pulse densities along the studied areas. This is

54 due to the fact that side-lap areas, where two or more flight lines overlap, have higher pulse

55 densities. These pulse density variations affect $\mathrm{L}_{\mathrm{D}}$-derived metrics and the subsequent forest

56 variables estimates and maps. Thus, a $\mathrm{L}_{\mathrm{D}}$-derived metric may have different values in two

57 samples with identical forest features but different pulse densities. Given that $\mathrm{L}_{\mathrm{D}}$-derived metrics

58 are used in regression models to estimate forest stand variables, the values of these variables will

59 be influenced as well.

60

61 The influence of $L_{D}$ pulse density on forest stand variable estimates was analyzed in several

62 studies (Table 1). All of these studies present variations in forest stand estimates, however, since

63 they were focused on different ecosystems and used different ranges of pulse densities, variations

64 have different scales. Gobakken and Naesset (2008), Magnussen et al. (2010) and Jakubowski et

65 al. (2013) observed that estimated variables were not significantly affected by density until 
66 dropping 0.25 points. $\mathrm{m}^{-2}$ in the first study, and 1 pulse $\mathrm{m}^{-2}$ in the last two. Analyzing specific 67 groups of variables, Magnussen et al. (2010), González-Ferreiro et al. (2012), Strunk et al. (2012), Treitz et al. (2012), Jakubowski et al. (2013) and Varo-Martínez et al. (2017) did not find 69 significant influence of pulse density on variables related to height, such as: mean, dominant, tree and Lorey's height, and mean height to live crown. According to Strunk et al. (2012) and

71 Treitz et al. (2012), variables related to tree density (i.e. number of stems and stem density) were 72 not significantly affected either, however, Magnussen et al. (2010) observed on the reliability 73 ratio that stem density was affected using low pulse densities. The reliability ratio was defined by 74 Hansen et al. 2015 as the variance of a metric among sample plots divided by the total variance 75 of the metric (i.e. the variance among sample plots plus the average variance within the plot). 76 Regarding variables related to trunk size, such as quadratic mean diameter (Treitz et al., 2012), 77 diameter at breast height (Jakubowski et al., 2013), and basal area (Magnussen et al., 2010; 78 González-Ferreiro et al., 2012; Stunk et al., 2012; Treitz et al., 2012; Jakubowski et al., 2013; 79 Ruiz et al., 2014; Varo-Martínez et al., 2017), had no significant differences between different 80 pulse densities, except for the basal area in a tropical forest in a study carried out by Manuri et al. 81 (2017). Among volume variables (i.e. volume over bark, stem volume, gross total and 82 merchantable volume), only volume over bark in González-Ferreiro et al. (2012) was 83 significantly affected by pulse density variations. Additionally, Jakubowski et al. (2013) for 84 shrub cover and height variables, Ruiz et al. (2014) for canopy cover, and Silva et al. (2017) for 85 aboveground carbon, observed that they were not significantly affected either. Lastly, stem 86 biomass and aboveground biomass were influenced by $L_{D}$ pulse density in an Atlantic and a 87 Tropical forest (González-Ferreiro et al., 2012; Manuri et al., 2017), but Treitz et al. (2012) did 88 not find significant differences in aboveground biomass in a Boreal forest using different 
89 densities. Overall, aboveground biomass is more influenced by pulse density than height 90 variables, although another factor affecting tree density, basal area and volume is the type of 91 ecosystem.

93 While the influence of pulse density on forest stand variables estimated from $\mathrm{L}_{\mathrm{D}}$-derived metrics 94 has been widely studied in different ecosystems, less attention has been paid to how $\mathrm{L}_{\mathrm{D}}$-derived 95 metrics are influenced. Roussel et al. (2017) mentioned that even when the values of estimated 96 variables are stable for different pulse densities, $\mathrm{L}_{\mathrm{D}}$-derived metrics are affected, since they are 97 measures and are not statistically fitted. Gobakken and Naesset (2008) and other authors, such as 98 Hansen et al. (2015) and Roussel et al. (2017), analyzed the effects of pulse density on $\mathrm{L}_{\mathrm{D}^{-}}$ 99 derived metrics. The first study computed height (e.g. percentiles, maximum, mean and 100 coefficient of variation) and density metric differences between the initial point density (i.e. 1.13

101 points. $\mathrm{m}^{-2}$ ) and thinned data (i.e. $0.25,0.13$ and 0.06 points. $\mathrm{m}^{-2}$ ) at different sample sizes. They 102 observed that the maximum height metric had large variations between point densities, these 103 variations being even larger when point density decreased. The remaining metrics did not have a 104 clear pattern. Hansen et al. (2015) computed seven $\mathrm{L}_{\mathrm{D}}$-derived metrics: mean, maximum, 105 variance, percentiles 10 and 90 of the above ground heights, and the proportion of points above 106 the ground and above the mean. They observed that most of the metrics were not influenced by 107 pulse densities, except for the maximum elevations that decreased with lower pulse densities. 108 However, the reliability ratio increased for all metrics when pulse density increased until 109 reaching a threshold where it remained stable. A possible explanation for this might be that mean 110 values of $\mathrm{L}_{\mathrm{D}}$-derived metrics did not vary much due to pulse density. In contrast, the standard 111 deviation increased for lower pulse densities, and hence the reliability ratio varied as well. 
112 Roussel et al. (2017) also analyzed how maximum height varied for different pulse densities.

113 They concluded that metric variations were not only subject to pulse density, but additionally to

114 LiDAR footprint size and canopy shape. The flatter the top canopy (i.e. fewer singularities), the 115 lesser difference between pulse densities.

116

117 
118 Table 1. Summary of existing studies about the influence of discrete LiDAR pulse density on forest stand estimates.

\begin{tabular}{|c|c|c|c|c|c|}
\hline Study & Study Area & Ecosystem & $\begin{array}{c}\text { Highest (HD) - lowest } \\
\text { (LD) densities } \\
\left(\text { pulses }^{\cdot} \mathbf{m}^{-2}\right) \\
\end{array}$ & Estimated variables & Results: HD-LD \\
\hline $\begin{array}{c}\text { Gobakken and Naesset } \\
(\mathbf{2 0 0 8 )}\end{array}$ & Våler, Southeastern Norway & Boreal forest & $1.13-0.06$ points. $\mathrm{m}^{-2}$ & $\begin{array}{l}\text { Hl: Lorey's height } \\
\text { BA: basal area } \\
\text { Vol: stand volume }\end{array}$ & $\begin{array}{l}\text { Estimate differences: } \\
\mathrm{Hl} \approx 0.2-0.6 \mathrm{~m} \\
\mathrm{BA} \approx 0.0-2.5 \mathrm{~m}^{2} \text {.ha- } 1 \\
\mathrm{Vol} \approx 5-30 \mathrm{~m}^{2} . \text { ha- } 1\end{array}$ \\
\hline Magnussen et al. (2010) & $\begin{array}{c}\text { Aurskog-Høland, Southeastern } \\
\text { Norway }\end{array}$ & Boreal forest & $2-0.25$ & $\begin{array}{l}\text { Hl: Lorey’s height } \\
\text { BA: basal area } \\
\text { V: volume over bark } \\
\text { SD: stem density }\end{array}$ & $\begin{array}{c}\mathrm{R}^{2}(\%): \\
\mathrm{BA} \approx 79-72 \\
\mathrm{~V} \approx 85-80 \\
\text { Reliability ratio: } \\
\mathrm{Hl} \approx 1.0-0.9 \\
\mathrm{BA} \approx 0.98-0.95 \\
\mathrm{~V} \approx 0.96-0.92 \\
\mathrm{SD} \approx 0.96-0.81\end{array}$ \\
\hline $\begin{array}{c}\text { González-Ferreiro et al. } \\
\text { (2012) }\end{array}$ & Galicia, Northwestern Spain & Atlantic forest & $8-0.5$ & $\begin{array}{l}\text { Hm: mean height } \\
\text { Hd: dominant height } \\
\text { BA: basal area } \\
\text { V: volume over bark } \\
\text { Wcr: crown biomass } \\
\text { Wst: stem biomass } \\
\text { AGB: aboveground biomass }\end{array}$ & $\begin{array}{c}\mathrm{R}^{2}(\%): \\
\mathrm{Hm}=78.6-75.9 \\
\mathrm{Hd}=84.6-86.5 \\
\mathrm{BA}=67.8-69.2 \\
\mathrm{~V}=69.1-79.4 \\
\mathrm{Wcr}=68.7-68.8 \\
\mathrm{Wst}=73.2-82.7 \\
\mathrm{AGB}=74.6-80.4\end{array}$ \\
\hline Strunk et al. (2012) & Western Washington State, USA & $\begin{array}{l}\text { Humid temperate - Pacific } \\
\text { lowland mixed forest }\end{array}$ & $3-0.05$ & ST: number of stems & $\begin{array}{l}\text { nRMSE (\%): } \\
\mathrm{ST} \approx 56-57\end{array}$ \\
\hline Treitz et al. (2012) & Ontario, Canada & Boreal forest & $3.2-0.5$ & $\begin{array}{c}\text { Hm: mean height } \\
\text { TH: tree height } \\
\text { QMD: quadratic mean diameter } \\
\text { BA: basal area } \\
\text { GTV: gross total volume } \\
\text { GMV: gross merchantable volume } \\
\text { AGB: aboveground biomass } \\
\text { SD: stem density }\end{array}$ & $\begin{array}{c}\mathrm{R}^{2}(\%) \text { : } \\
\text { Black spruce }(\mathrm{BS}), \text { Intolerant hardwood }(\mathrm{IH}) \text {. } \\
\text { Hm }=95.1-93.6(\mathrm{BS}) ; 76.7,77.3(\mathrm{IH}) \\
\mathrm{TH}=92.3,90.3(\mathrm{BS}) ; 94.1,94.3(\mathrm{IH}) \\
\text { QMD }=83.8,86.3(\mathrm{BS}) ; 84.2,84.0(\mathrm{IH}) \\
\mathrm{BA}=91.8,93.5(\mathrm{BS}) ; 83.7,82.3 \\
\text { GTV }=94.9,94.2(\mathrm{BS}) ; 83.7,82.3(\mathrm{IH}) \\
\text { GMV }=91.6,93.9(\mathrm{BS}) ; 87.3,87.7(\mathrm{IH}) \\
\text { AGB }=92.5,93.2(\mathrm{BS}) ; 78.8,77.5(\mathrm{IH}) \\
\mathrm{SD}=88.8,86.1(\mathrm{BS}) ; 23.9,24.8(\mathrm{IH})\end{array}$ \\
\hline
\end{tabular}


120 Table 1 (cont.). Summary of existing studies about the influence of discrete LiDAR pulse density on forest stand estimates.

\begin{tabular}{|c|c|c|c|c|c|}
\hline Study & Study Area & Ecosystem & $\begin{array}{c}\text { Highest (HD) - lowest } \\
\text { (LD) densities } \\
\left(\text { pulses }^{\cdot} \mathbf{m}^{-2}\right)\end{array}$ & Estimated variables & Results: HD-LD \\
\hline Jakubowski et al. (2013) & $\begin{array}{c}\text { Tahoe National Forest. Northern } \\
\text { California, USA }\end{array}$ & Mediterranean-climate forest & $9-0.01$ & $\begin{array}{c}\text { TH: tree height } \\
\text { HTLCB: mean height lo live } \\
\text { crown base } \\
\text { BA: basal area } \\
\text { DBH: diameter at breast height } \\
\text { SC: shrub cover } \\
\text { SH: shrub height }\end{array}$ & $\begin{array}{c}\mathrm{R}^{2}(\%): \\
\mathrm{TH}=86.8-52.4 \\
\mathrm{HTLCB}=76.8-28.8 \\
\mathrm{BA}=77.5-48.9 \\
\mathrm{DBH}=59.7-38.0 \\
\mathrm{SC}=53.1-11.9 \\
\mathrm{SH}=45.9-29.0\end{array}$ \\
\hline Ruiz et al. (2014) & $\begin{array}{c}\text { La Serranía de Cuenca, Central } \\
\text { Spain }\end{array}$ & Mediterranean mountain forest & $6-0.25$ points. $\mathrm{m}^{-2}$ & $\begin{array}{c}\text { V: volume } \\
\text { AGB: aboveground biomass } \\
\text { BA: basal area } \\
\text { CC: canopy cover }\end{array}$ & $\begin{array}{c}\mathrm{R}^{2}(\%)(\text { with a plot radius of } 16 \mathrm{~m}) \\
\mathrm{V} \approx 90.5-86.0 \\
\mathrm{AGB} \approx 85.5-82.0 \\
\mathrm{BA} \approx 87.0-83.0 \\
\mathrm{CC} \approx 89.0-89.0\end{array}$ \\
\hline Manuri et al. (2017) & Central Kalimantan, Indonesia & Tropical forest & $2.8-0.01$ points. $\mathrm{m}^{-2}$ & $\begin{array}{l}\text { AGB: aboveground biomass } \\
\text { BA: basal area }\end{array}$ & $\begin{array}{c}\mathrm{R}^{2}(\%): \\
\mathrm{AGB} \approx(90.0)-(80.0,60.0) \\
\mathrm{BA} \approx(90.0)-(70.0,40.0)\end{array}$ \\
\hline Silva et al. (2017) & Paraíba Valley, São Paulo, Brazil & Humid subtropical forest & $10-5$ & AGC: aboveground carbon & $\begin{array}{c}\mathrm{R}^{2}(\%): \\
\mathrm{AGC}=82.17-81.79\end{array}$ \\
\hline $\begin{array}{l}\text { Varo-Martínez et al. } \\
\text { (2017) }\end{array}$ & $\begin{array}{l}\text { Sierra de Los Filabres, } \\
\text { Southeastern Spain }\end{array}$ & Semi-arid Mediterranean forest & $10-0.5$ & $\begin{array}{l}\text { Hd: dominant height } \\
\text { BA: basal area }\end{array}$ & $\begin{array}{c}\mathrm{R}^{2}(\%): \\
\mathrm{Hd}=(97.0,94.0)-(95.0,93.0) \\
\mathrm{BA}=(92.0,88.0)-(93.0,87.0)\end{array}$ \\
\hline
\end{tabular}


122 Differences in data characteristics between $\mathrm{L}_{\mathrm{D}}$ and $\mathrm{L}_{\mathrm{FW}}$ requires different pre-processing. While

$123 \mathrm{~L}_{\mathrm{D}}$-derived metrics can be recomputed by simply varying the number of points (i.e. pulse

124 density), LFw data pre-processing is more complex and there are other parameters that may also

125 be considered. This complexity can explain why the influence of pulse density on LFw-derived

126 metrics and forest stand variable estimates has received less attention (Crespo-Peremarch et al.,

127 2016). Furthermore, few published studies have analyzed the evolution of FW-derived metrics

128 by artificially reducing the pulse density. Crespo-Peremarch et al. (2016) observed $\mathrm{L}_{\mathrm{FW}}$-derived

129 metric differences (namely "side-lap effect") in adjacent areas that were compared pairwise, with

130 similar forest features but having different densities. It was found that $\mathrm{L}_{\mathrm{FW}}$-derived metrics were

131 influenced by density variations caused by flight stripe side-lap areas. A standard pre-processing

132 method for $\mathrm{LFW}_{\mathrm{FW}}$-derived metric extraction is voxelization (Hermosilla et al., 2014b). LiDAR

133 return pulses are clustered into voxels (e.g. rectangular prisms), whose values are computed as

134 the statistics (i.e. maximum, mean, median, etc.) of return pulse amplitude values of waveforms

135 within the voxels. These voxel columns of values from the top tree to the ground describe the

136 pseudo-vertical waveform, which corrects the registered scan angle (Hermosilla et al., 2014b).

137 Once pseudo-vertical waveform is generated, LFW-derived metrics can be extracted. Changing

138 the voxel size and the assignation value may diminish the side-lap effect without modifying the

139 pulse density. As mentioned above, increasing the voxel size reduces the number of empty

140 voxels, avoiding gaps in the pseudo-vertical waveforms. On the other hand, changing the

141 assignation value can avoid outliers from amplitude values, which is more likely when the voxel

142 size increases.

143 
144 Crespo-Peremarch et al. (2016) and Crespo-Peremarch and Ruiz (2018) observed that the side145 lap effect in $\mathrm{LFW}_{\mathrm{FW}}$-derived metrics had an effect on forest stand variable estimates as well, given 146 that the latter are estimated through $\mathrm{L}_{\mathrm{FW}}$-derived metrics. The first study visually observed these 147 differences for a large area, while the latter observed that $\mathrm{R}^{2}$ values of aboveground biomass and 148 canopy base height between different pulse densities differed by $3 \%$ and $5 \%$, respectively, for a 149 voxel size of $0.25 \mathrm{~m}$. Therefore, forest stand variables were wrongly mapped with the side-lap 150 effect due to pulse density variation. Therefore, correcting side-lap effect is essential to properly 151 estimate forest stand variables. Comparing $\mathrm{L}_{\mathrm{FW}}$-derived metrics obtained using different pulse 152 densities may help to better understand how metrics are influenced and to reduce side-lap effect.

154 The aim of this paper is to analyze LFw-derived metric variations when pulse density, voxel size 155 and assignation value are modified. To do this, we randomly diminished pulse density from 16 to 1562 pulses $\mathrm{m}^{-2}$ every 1 pulse $\mathrm{m}^{-2}$ in a set of 30 samples. In addition, for each density we computed 157 six $\mathrm{L}_{\mathrm{FW}}$-derived metrics using five different assignation values (i.e. maximum, mean, median, 158 percentiles 90 and 95 ) and voxel sizes from 0.25 to $1.55 \mathrm{~m}$ every $0.10 \mathrm{~m}$. Moreover, the $\mathrm{L}_{\mathrm{FW}}-$ 159 derived metric values obtained at every pulse density for the different combinations of $L_{F W}$ 160 parameters was analyzed. Results will lead to a better understanding of the relation between LFW $_{F}$ 161 methodological parameters and pulse density in order to improve the use of these data and 162 techniques. 
166 The study area (2,258 ha) is located in Panther Creek (Oregon, USA) (Fig. 1a), in the Cascade 167 mixed forest ecoregion (Bailey, 1980). The dominant species is Douglas-fir (Pseudotsuga 168 menziesii) very occasionally mixed with other conifers such as western red cedar (Thuja plicata), 169 western hemlock (Tsuga heterophylla) and grand fir (Abies grandis), and broad-leaved species 170 such as bigleaf maple (Acer macrophyllum) and red alder (Alnus rubra). Tree heights are 171 variable due to harvesting, being up to $60 \mathrm{~m}$. Altitudes in the total extent of the study area range 172 from 100 to $700 \mathrm{~m}$.

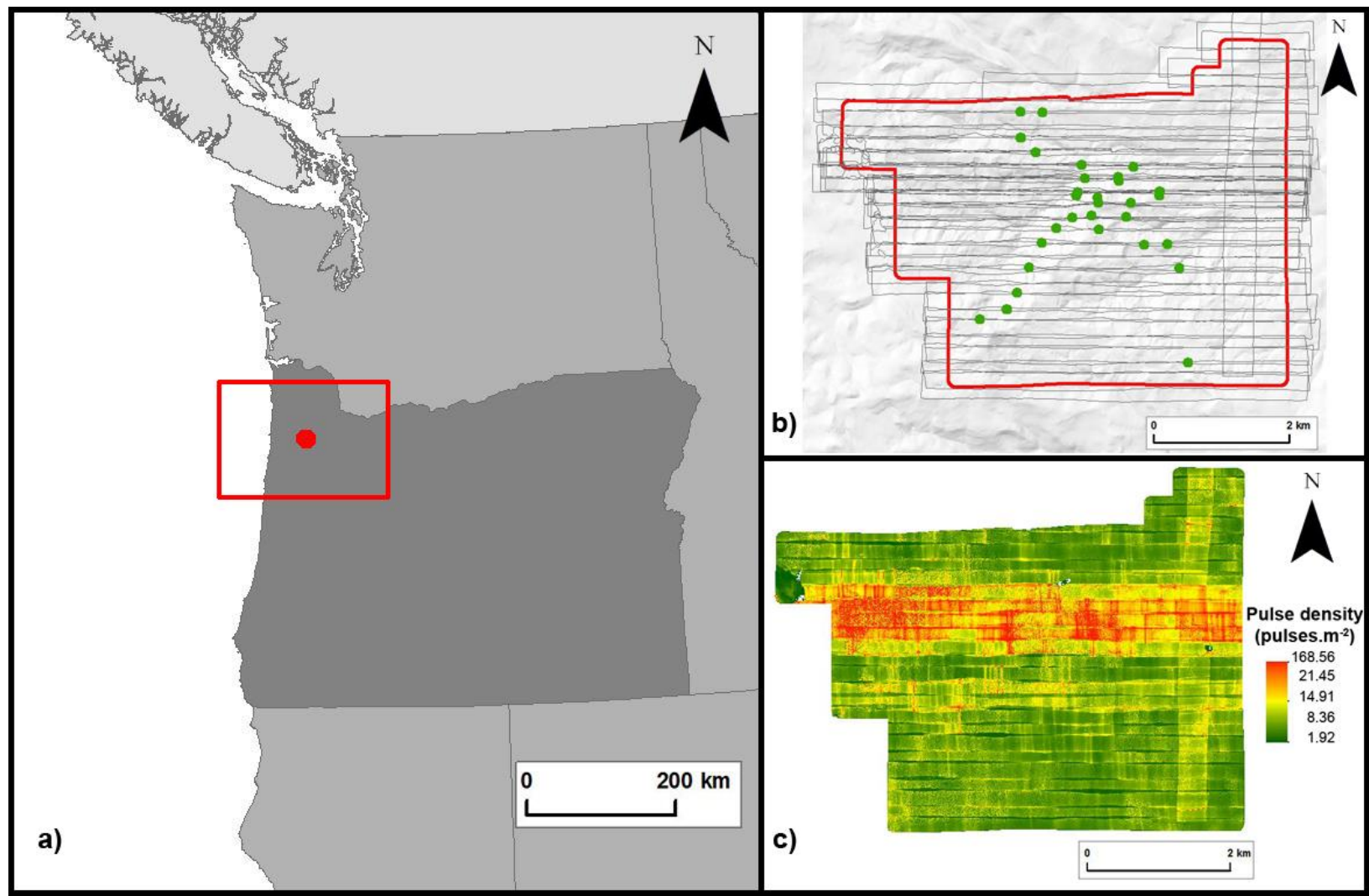

Fig. 1. (a) Study area location in the USA Pacific Northwest, (b) flight trajectories and sample locations (green) within the study area limits (red), and (c) pulse density. 


\subsection{LiDAR full-waveform Data}

\subsubsection{Data acquisition}

180

181

182

183

184

185

186

187

188

189

190

191

192

193

194

LFw data were acquired in July 2010 using a Leica ALS60 over 3,264.51 ha, with a pulse density ranging from 2 to 168 pulses $\mathrm{m}^{-2}$, and an average of 10.4 pulses $\mathrm{m}^{-2}$ (Fig. 1c). Data were registered at an average flight altitude of $900 \mathrm{~m}$ above ground level, at $105 \mathrm{kHz}$ pulse frequency, and with a scan angle of $\pm 14^{\circ}$ from nadir. The study area was covered with flight stripe side-lap of $\geq 50 \%$ ( $\geq 100 \%$ overlap). Waveform amplitudes were recorded in 256 bins with a temporal sample spacing of 2 ns (i.e. $0.3 \mathrm{~m}$ ) and a footprint size of $\approx 0.25 \mathrm{~m}$. In addition, a digital terrain

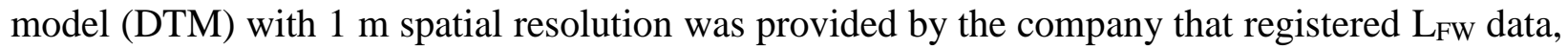
and its vertical accuracy assessed using 33 GPS ground control points, obtaining a RMSE of 0.19 m.

\subsubsection{Radiometric calibration and waveform denoising}

The overall processing followed in this paper is described in Fig. 2, and this is as follows:

Radiometric calibration is an essential pre-processing step of $\mathrm{L}_{\mathrm{FW}}$ data, since most of the metrics depend on the amplitude values. There are two main approaches of radiometric calibration: relative and absolute. While the former reduces radiometric differences between flight stripes without ground data, the latter reduces differences related to acquisition day conditions and sensors using target properties (Wagner, 2010). In this study, we applied a relative radiometric calibration, given that target properties from ground data were not available, and there were no paved roads with known radiometric values in the study area. Therefore, we corrected the amplitude values along the waveform using Eq. (1) described by Kashani et al. (2015) for non- 
200 extended objects, which corrects amplitude values taking into account the range from sensor to 201 object and the local incidence angle.

202

203

$$
A_{C}=A * \frac{R_{i}^{3}}{R_{r e f}{ }^{3}} * \frac{1}{\cos \alpha}
$$

204

205 where $A_{C}=$ corrected amplitude,

206

207

$A=$ amplitude to be corrected,

$R_{i}=$ range from the sensor to the object,

208

$R_{\text {ref }}=$ reference range set to $1000 \mathrm{~m}$ for this study,

209

$\alpha=$ local incidence angle.

210

211 Once waveforms were radiometrically corrected, noise was still present. In order to remove it,

212 we followed the denoising process described by Hermosilla et al. (2014b), consisting of applying

213 a noise threshold defined as the mean plus four times the standard deviation of the waveform

214 amplitude values (Lefsky et al., 2005), removing all lower values below the threshold.

215 Additionally, a Gaussian filter was used to reduce any remaining noise.

216 


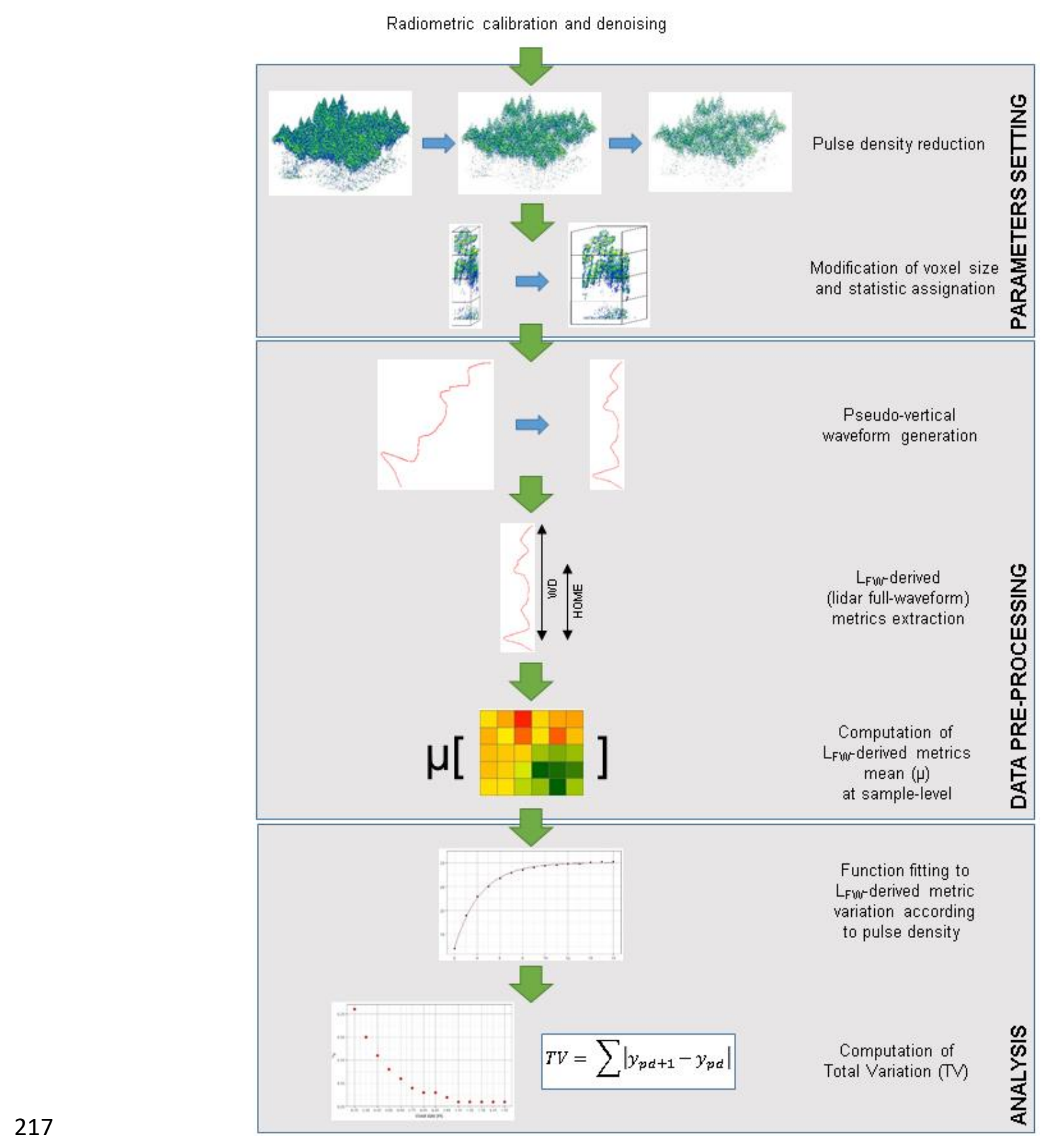

Fig. 2. Overall processing flowchart.

221 In order to carry out the analysis, a total of 30 samples were selected from the study area where

222 conifers were dominant (Fig. 1b). These samples were located where pulse density was higher in 223 order to be able to test a higher number of density variations. The polygon samples were square- 
224 shaped with an area of $804.25 \mathrm{~m}^{2}$ each, this is the equivalent area of $16 \mathrm{~m}$ radius circular plots.

225 The pulse density was reduced from 16 to 2 pulses $\mathrm{m}^{-2}$ with an interval of 1 pulse $\mathrm{m}^{-2}$, resulting in

22615 different density values. The initial pulse density was selected considering the maximum and

227 common pulse density value found in the 30 plots.

228 Pulse density was reduced randomly (Fig. 2) (i.e. from 16 to 2 pulses $\mathrm{m}^{-2}$ with an interval of 1

229 pulse $\mathrm{m}^{-2}$ ) and computed as the number of pulses contained in the polygon sample divided by the

230 area. To reduce pulse density, we calculated the number of pulses $(n)$ required in an area of

$231804.25 \mathrm{~m}^{2}$ to obtain a pulse density equal to $p$. Then, $n$ random pulses were kept for the analysis

232 and the rest were discarded.

233

234

\subsubsection{Metrics extraction}

235 Once pulses were denoised and randomly filtered based on established pulse densities, a height

236 normalization and a voxelization process from the waveform bins was carried out. The DTM

237 described above and generated from the original pulse densities was used for height

238 normalization. Regarding the voxelization process, we tested 14 voxel size variations in $\mathrm{XY}$

239 dimensions (Fig. 2): 0.25, 0.35, 0.45, 0.55, 0.65, 0.75, 0.85, 0.95, 1.05, 1.15, 1.25, 1.35, 1.45 and

$240 \quad 1.55 \mathrm{~m}$. The minimum voxel size was equal to the footprint size. The voxel size in $\mathrm{Z}$ dimension

241 was not modified, and the vertical distance between waveform bins, based on the temporal

242 sample spacing of the LiDAR system, was respected. Therefore, the voxel size in $\mathrm{Z}$ dimension

243 was $0.3 \mathrm{~m}$, equal to the temporal sample spacing. In addition, the voxel value was computed

244 (Fig. 2) using five different statistics (maximum, mean, median, percentiles 90 and 95) for all the

245 waveform bins within each voxel. As a result, every voxel had a value for these five statistics.

246 Afterwards, each column of voxels was computed separately. Voxel values from the top tree to

247 the ground describe a new waveform corrected from scan angle and called "pseudo-vertical" 
waveform (Hermosilla et al., 2014b) (Fig. 2). LFW-derived metrics were extracted from the

249 pseudo-vertical waveform (Fig. 2). The six $\mathrm{L}_{\mathrm{FW}}$-derived metrics used in this paper were

250 introduced by Duong (2010): HOME, WD, NP, ROUGH, RWE and FS (Table 2).

251

252 Table 2. Description of $\mathrm{L}_{\mathrm{FW}}$-derived metrics used in this study.

253

\begin{tabular}{|c|c|}
\hline Metric & Description \\
\hline HOME & $\begin{array}{l}\text { Height Of Median Energy: height where } \\
\text { the median of the return energy is reached }\end{array}$ \\
\hline WD & $\begin{array}{l}\text { Waveform Distance: height from } \\
\text { the ground to the beginning of the waveform }\end{array}$ \\
\hline NP & Number of Peaks: number of peaks of the waveform \\
\hline ROUGH & $\begin{array}{l}\text { ROUGHness of outermost canopy: distance from } \\
\text { the beginning of the waveform to the first peak }\end{array}$ \\
\hline RWE & Return Waveform Energy: sum of waveform amplitudes \\
\hline FS & $\begin{array}{l}\text { Front Slope angle: vertical angle from } \\
\text { the beginning of the waveform and the amplitude of the first peak }\end{array}$ \\
\hline
\end{tabular}

255 As a result, each column of voxels had a pseudo-vertical waveform, and therefore a value for 256 each $\mathrm{L}_{\mathrm{FW}}$-derived metric. Finally, the $\mathrm{L}_{\mathrm{FW}}$-derived metric value for each sample was computed as

257 the average of all the voxel columns within each polygon sample (Fig. 2).

258

2.3. Analysis of metrics variation

2.3.1. $\mathrm{LFW}_{\mathrm{FW}}$-derived metric variation related to pulse density

261 Once LFw-derived metrics were computed for every sample, voxel size, assignation value and 262 pulse density, we analyzed its variation related to the pulse density (Fig. 2). The goal was to 263 analyze $\mathrm{L}_{\mathrm{FW}}$-derived metric variations modifying the three mentioned parameters (i.e. voxel size, 264 assignation value and pulse density). We first observed the variation related to pulse density for 
several samples at different voxel sizes and assignation values. As this variation followed a negative exponential distribution, we used the least squares method to find the most appropriate parameter values, fitting a negative exponential model (Eq. (2)). In this model, based on the exponential semivariogram model (David, 1977), LFW-derived metric values ( $\mathrm{y}=\mathrm{dependent}$ variable) tend to remain stable around a sill with a slight positive slope at a given pulse density $(\mathrm{x}=$ independent variable). The formula of the negative exponential function is as follows:

where $x=$ value of density in pulses $\mathrm{m}^{-2}$, $y=$ value of the $\mathrm{LFW}_{\mathrm{FW}}$-derived metric, $a=$ value of $y$ at which $x=0$ in the negative exponential model, $b=$ value of $x$ where $y$ reaches the $95 \%$ of the sill value, $c=$ range of $y$ between $a$ and the value of $y$ at which the function is stabilized then, $a+c=y$ value of the sill.

On the other hand, each sample has different values for $\mathrm{L}_{\mathrm{FW}}$-derived metrics, due to vegetation variability. Therefore, with the aim of working with all 30 samples we did not fit a function for all the samples together. Instead, we fit a function for each sample individually, and then we averaged the model results from the 30 samples clustered by LFw-derived metric, voxel size and assignation value. As a result, we computed 12,600 different models (i.e. 30 samples $\times 6 \mathrm{LFW}^{-}$ derived metrics $\times 14$ voxel sizes $\times 5$ assignation values) resulting 420 averaged results (i.e. 6 $\mathrm{L}_{\mathrm{FW}}$-derived metrics $\times 14$ voxel sizes $\times 5$ assignation values). Only negative exponential models 
288 with a convergence tolerance of $<1 \times 10^{-5}$ in the iterative fitting process were used for the study.

289 Validation was carried out using the Jackknife procedure described by Duda et al. (2012), which

290 utilizes a leave-one-out procedure. Results were evaluated using the coefficient $b$, which shows

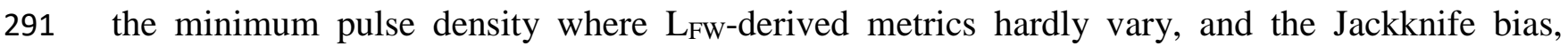

292 which shows the average of the deviations after removing one observation at each iteration.

293

294

2.3.2. LFW-derived metric variation according to voxel size and assignation value

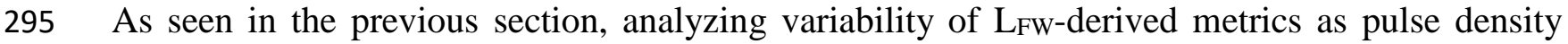

296 increases provides the minimum pulse density (MPD) where metrics stay steady, corresponding

297 to the coefficient $b$ of the negative exponential model. In addition, analyzing the variability using 298 different voxel sizes and assignation values may help to diminish the influence of the pulse 299 density (Crespo-Peremarch et al., 2016). Total Variation (TVar) (Eq. (3)) (Harten, 1983) can be 300 used instead of the variability of $\mathrm{LFW}_{\mathrm{FW}}$-derived metric values for the different pulse densities (Fig. 301 2), explained in the previous section. The TVar computes the sum of differences between 302 adjacent values. Hence, the lower the TVar value, the less variability the $\mathrm{L}_{\mathrm{FW}}$-derived metric has 303 due to the pulse density. The formula of the TVar is as follows:

$$
\text { TVar }=\sum_{p d=2}^{16-1}\left|y_{p d+1}-y_{p d}\right|
$$

307 where $y=$ value of the metric in a given pulse density $(p d)$ and,

$$
p d=\text { pulse density. }
$$


310 Given that $\mathrm{L}_{\mathrm{FW}}$-derived metrics and assignation values have, in practice, a different range of 311 values, $\mathrm{L}_{\mathrm{FW}}$-derived metrics were rescaled independently for each possible combination of metric 312 and assignation type. A modified version of the feature scaling method was used (Eq. (4)) to 313 standardize data. In our case, the minimum value was equal to zero, since we wanted to keep the 314 minimum TVar value as zero:

$$
y=\frac{x-\min (x)}{\max (x)-\min (x)} / \min (\mathrm{x})=0
$$

where $y=$ standardization of the $\mathrm{L}_{\mathrm{FW}}$-derived metric value, $x=\mathrm{L}_{\mathrm{FW}}$-derived metric value, assignation value, in our case modified to $\min (x)=0$, $\max (x)=$ maximum $\mathrm{LFW}_{\mathrm{FW}}$-derived metric value grouped by $\mathrm{LFW}_{\mathrm{FW}}$-derived metric and assignation value.

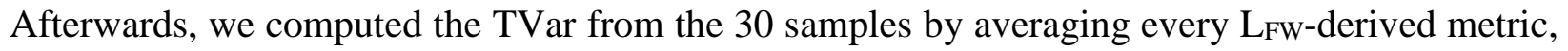
voxel size and assignation value.

Fig. 3 shows how the pseudo-vertical waveform and the $\mathrm{L}_{\mathrm{FW}}$-derived metrics from the same voxel column vary modifying the pulse density, voxel size and assignation value. The lower the pulse density, the more null values and the less detail appear in the pseudo-vertical waveform. 
332 However, changes in the waveform due to pulse density reduction seem to be less noticeable 333 when voxel size increases to $1.25 \mathrm{~m}$, except for the median assignation value. In addition, 334 pseudo-vertical waveforms using the median assignation are smoother than those using the 335 maximum assignation.

336 Analyzing LFW-derived metric values for the same voxel size, HOME, WD, ROUGH and FS do 337 not show significant variations. On the contrary, NP and RWE are more variable. 


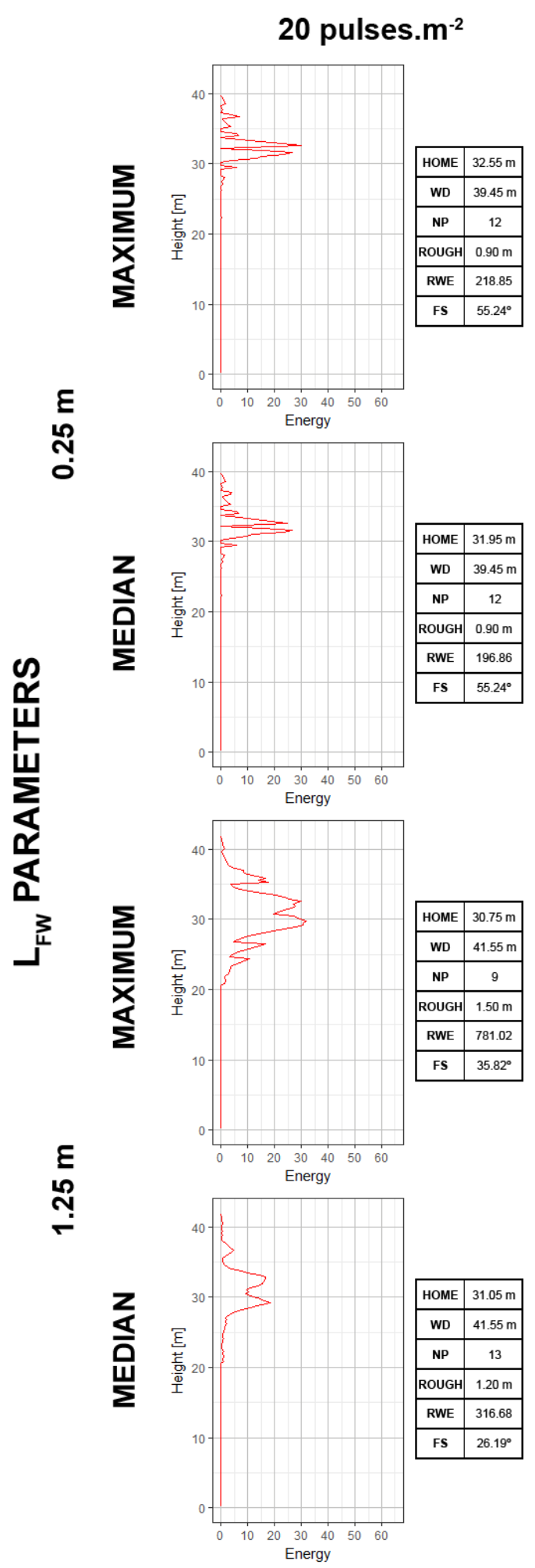

PULSE DENSITY
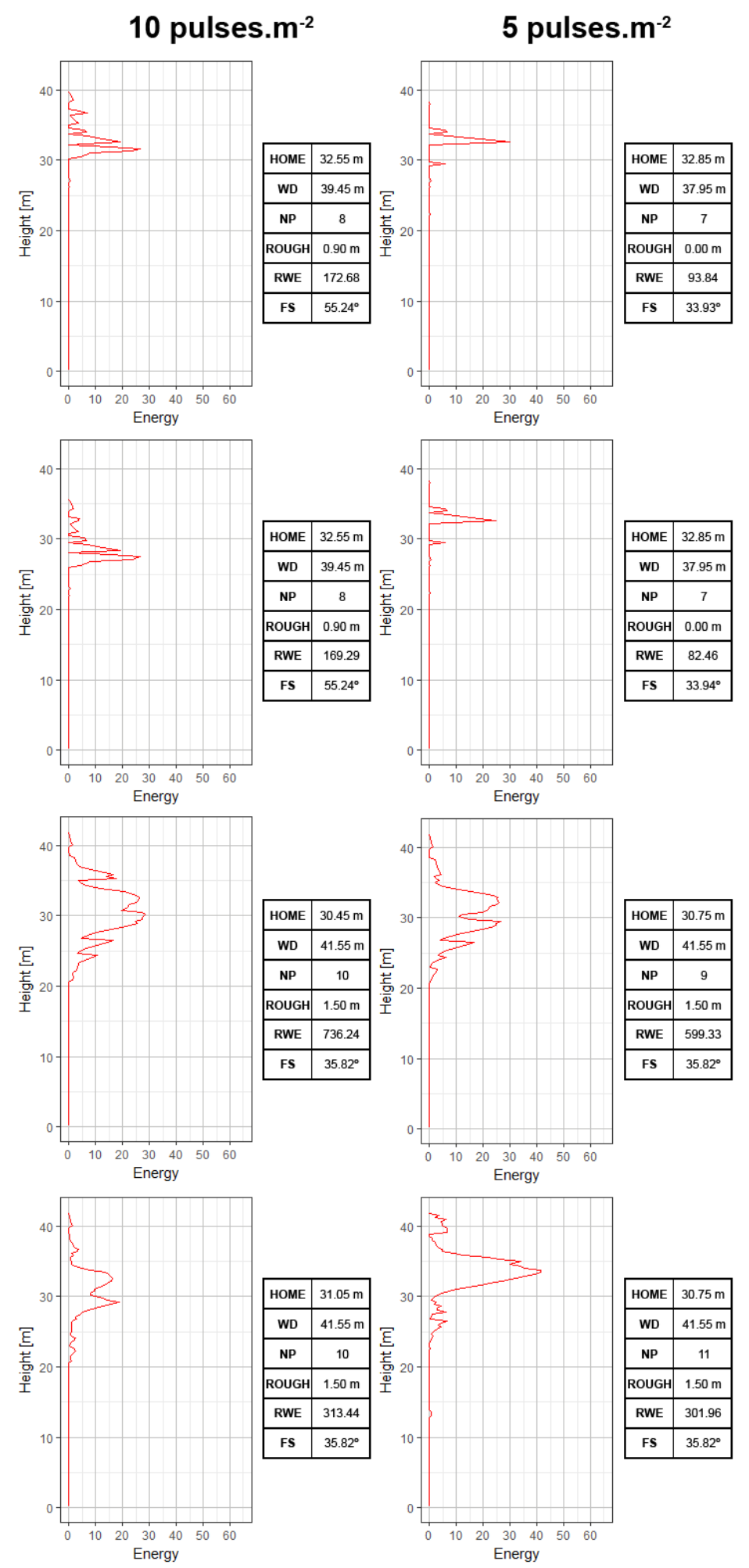

Fig. 3. Examples of pseudo-vertical waveforms at voxel column-level and $L_{F W}$-derived metric values for different pulse densities (20, 10 and 5 pulses $\left.m^{-2}\right)$, voxel sizes $(0.25$ and 1.25 m) and assignation values (maximum and median). 
3.1. Analysis of $\mathrm{L}_{\mathrm{FW}}$-derived metric variation related to pulse density

344

345

a)

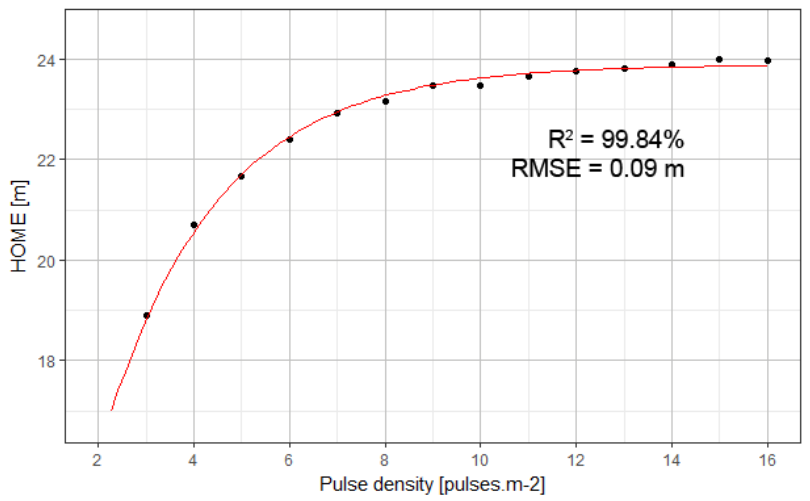

b)

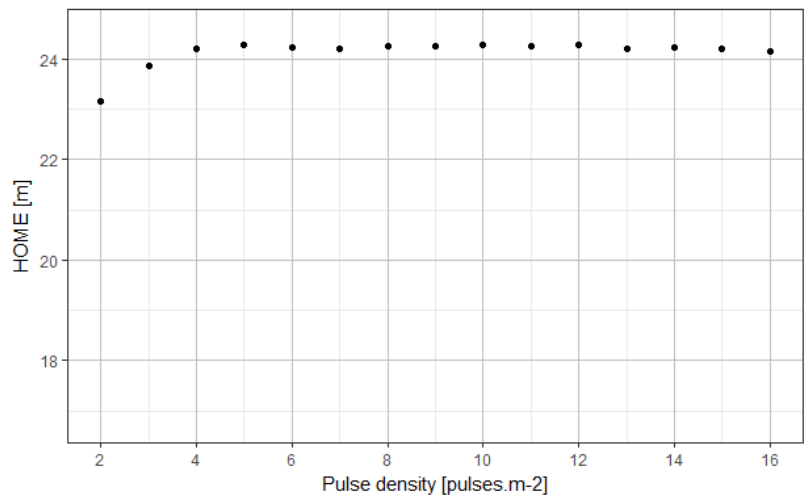

Fig. 4. Variation of HOME related to pulse density in one sample for the maximum assignation value and voxel sizes of (a) $0.25 \mathrm{~m}$ and (b) $0.75 \mathrm{~m}$. The black points represent the values computed and the red curve the fitted model, being (a) negative exponential. The values of HOME in (b) do not fit a negative exponential model.

361 (i.e., the $b$ coefficients from the negative exponential models (see Eq. (2))); and Fig. 5b shows 
362 the standard deviation of the MPD for all samples. All the models obtained a Jackknife bias

363 lower than $1.56 \cdot 10^{-13}$ in the validation procedure for the three coefficients of the negative 364 exponential model (e.g. a, b, and c). This means that there were not outliers after applying the 365 leave-one-out procedure. It is important to remark that negative exponential models were 366 generated using sample data from 2 to 16 pulses $\mathrm{m}^{-2}$. Hence, $\mathrm{L}_{\mathrm{FW}}$-derived metric variation values 367 estimated out of this range are extrapolations, and as such the resulting MPD values higher than 36816 pulses $\mathrm{m}^{-2}$ must be considered carefully. Additionally, empty cells in Fig. 5 correspond to 369 combinations of metrics and voxel sizes that do not fit a negative exponential model. NP, 370 ROUGH and RWE are the metrics with highest MPD values (MPD $€[42.2,46.2]$, MPD $\epsilon$ [18.7, $37121.3]$ and MPD $\epsilon[60.2,89.7]$ pulses $\mathrm{m}^{-2}$, respectively, for a voxel size of $\left.0.25 \mathrm{~m}\right)$, while HOME, 372 WD and FS have the lowest (MPD $\epsilon$ [7.1, 7.2], MPD = 9.6 and MPD $\epsilon[3.9,4.1]$ pulses $\mathrm{m}^{-2}$, 373 respectively, for a voxel size of $0.25 \mathrm{~m}$ ). Every $\mathrm{L}_{\mathrm{FW}}$-derived metric remains asymptotically stable 374 at lower pulse densities as voxel size increases. For instance, the MPD decreases from 7.1 to 3.4 375 pulses $\mathrm{m}^{-2}$ for HOME; from 9.6 to 8.4 pulses $\mathrm{m}^{-2}$ for $\mathrm{WD}$; from 45.5 to 15.4 pulses $\mathrm{m}^{-2}$ for NP; 376 from 21 to 4.6 pulses $\mathrm{m}^{-2}$ for ROUGH; and from 60.2 to 5.3 pulses $\mathrm{m}^{-2}$ for RWE. However, WD 377 has low values for voxel sizes of 0.35 and $0.45 \mathrm{~m}$ (MPD $\epsilon[8.4,8.5])$, but they increase again as 378 the voxel size also increases $\left(\mathrm{MPD}=13.5\right.$ pulses $\mathrm{m}^{-2}$ ). Results also show that for low MPD 379 values (i.e. MPD $\in[3.9,5.6])$, $\mathrm{L}_{\mathrm{FW}}$-derived metric variation does not fit a negative exponential 380 trend for high voxel sizes. This behavior is observed with HOME, ROUGH, RWE and FS, 381 except for ROUGH using the maximum assignation value. In these cases, LFw-derived metric 382 values tend to slightly decrease as pulse density increases.

383 Comparing different assignation values, HOME, WD, NP and FS have similar MPD values; 384 however, ROUGH and RWE were influenced differently. Both ROUGH and RWE remain stable 
385 at lower pulse densities using the median as assignation value, but they present more variation 386 using the maximum, percentiles 90 and 95. For instance, RWE has a MPD value of 5.3 pulses $\mathrm{m}^{-}$

3872 using the median assignation and a voxel size of $1.25 \mathrm{~m}$, while the MPD value was 18.6 using 388 the maximum and the same voxel size.

389 Analyzing the average of the standard deviation of the MPD from the 30 samples (Fig. 5b), all 390 the values are low (between 1 and 2.6 pulses $\mathrm{m}^{-2}$ ) except for NP and RWE with small voxel 391 sizes. These $\mathrm{L}_{\mathrm{FW}}$-derived metrics have large standard deviations for small voxel sizes ([6.7, 8.6] 392 and $[5.8,11]$ pulses $\mathrm{m}^{-2}$, respectively), diminishing the values for larger voxel sizes $([1.9,2.3]$ 393 and $[1.0,1.2]$ pulses $\mathrm{m}^{-2}$, respectively). However, the standard deviation of ROUGH using the 394 maximum assignation increases as voxel size increases. High standard deviation values of MPD 395 are related to high MPD values. 


\section{Voxel size $(m)$}

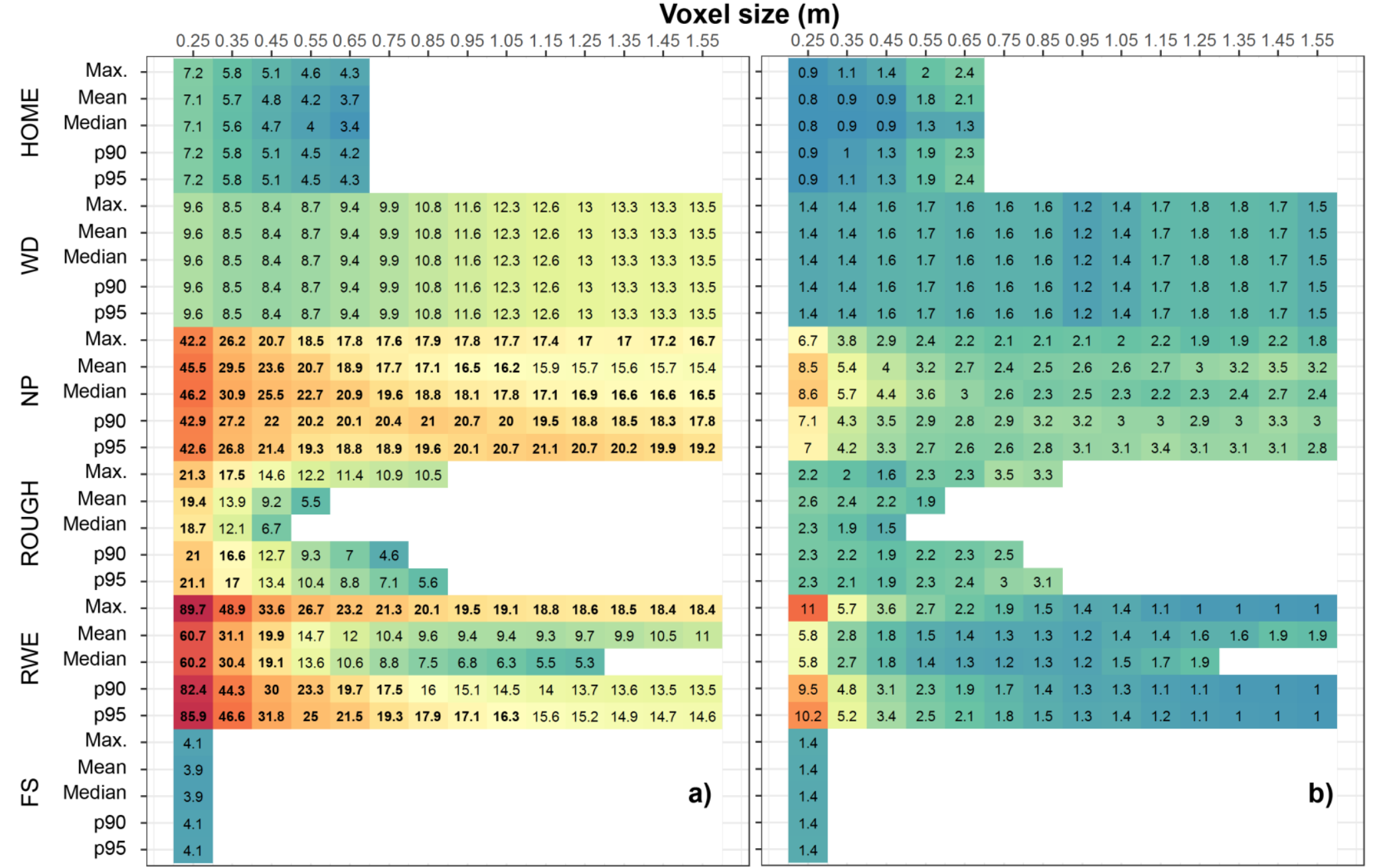

Fig. 5. (a) Average minimum pulse density (MPD; i.e. coefficient b from the negative exponential model) from the 30 samples for different voxel sizes and assignation values. Empty cells correspond to combinations of metrics and voxel sizes that do not fit a negative exponential model. Values in bold correspond to MPD values higher than 16 pulses $\mathrm{m}^{-2}$ (i.e. the maximum pulse density from sample data used to generate the negative exponential model). (b) Average standard deviation of MPD for the 30 samples tested. Smallest and highest values are represented by blue and red colors, respectively. 

value

404 Fig. 6 shows the Total Variation standardized (TVar) value defined by Eq. (3) and (4) for every 405 LFW-derived metric computed at the different voxel sizes and assignation values. Overall, 406 HOME, WD and FS present the lowest TVar values (TVar $\epsilon[0.03,0.27]$, TVar $\epsilon[0.06,0.28]$ and 407 TVar $\epsilon[0.10,0.28]$, respectively), while NP, ROUGH and RWE present higher values (TVar $\epsilon$ $408[0.24,0.36]$, TVar $\epsilon[0.14,0.52]$ and TVar $\epsilon[0.012,0.45]$, respectively, using small voxel sizes). 409 TVar values of HOME, WD, NP for maximum, RWE for mean and median, and FS, decrease as 410 voxel size increases compared to the lowest voxel size (i.e. $0.25 \mathrm{~m}$ ). These values range from 4110.27 to 0.04 for HOME, from 0.28 to 0.06 for $\mathrm{WD}$, from 0.33 to 0.30 for NP with the maximum 412 assignation value; from $[0.40,0.45]$ to $[0.12,0.17]$ for RWE with the mean and median 413 assignation values; and from $[0.26,0.28]$ to $[0.10,0.14]$ for FS. NP TVar values do not vary 414 significantly as voxel size increases, the values being [0.24, 0.32] at $0.25 \mathrm{~m}$, and $[0.27,0.30]$ the 415 lowest TVar values at other voxel sizes. Regarding RWE, the TVar values are minimal at the 416 lowest voxel size using the maximum, percentiles 90 and 95 as assignation values. Nevertheless, 417 TVar values are particularly high at the lowest voxel size using the mean and median assignation 418 value, and become low for the largest voxel sizes, especially with the median. In addition, TVar 419 values from ROUGH steeply increase as voxel size increases, varying from $[0.14,0.23]$ at 0.25 $420 \mathrm{~m}$ to $[0.38,0.52]$ at $1.55 \mathrm{~m}$.

421 Regarding the assignation values, HOME and WD present little or no differences. However, NP, 422 ROUGH and RWE have different TVar values depending on the assignation values. NP has the 423 lowest value at $0.25 \mathrm{~m}$ for the median assignation value (TVar $=0.24)$. The lowest TVar values 424 of ROUGH are reached using the maximum, percentiles 90 and 95. Finally, RWE TVar values 
425 have the largest differences between assignation values, the mean and median being completely 426 different from the others.

\begin{tabular}{|c|c|c|c|c|c|c|c|c|c|c|c|c|c|c|c|}
\hline & & 0.2 & & & & & 0 & $\mathrm{e}$ & 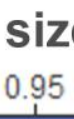 & $(n$ & m) & 1.2 & 3 & 14 & 1.55 \\
\hline & Max. & 0.28 & 0.18 & 0.13 & 0.09 & 0.08 & .08 & 0.05 & 0.05 & 0.05 & 0.04 & 0.03 & 0.04 & 0.04 & 0.06 \\
\hline Ш & Mean & 0.27 & 0.18 & 0.13 & 0.09 & 0.08 & 0.08 & 0.05 & 0.05 & 0.05 & 0.04 & 0.04 & 0.04 & 0.04 & 0.06 \\
\hline ○ิ & Median & 0.27 & 0.18 & 0.13 & 0.09 & 0.08 & 0.06 & 0.05 & 0.08 & 0.05 & 0.04 & 0.04 & 0.05 & 0.05 & 0.07 \\
\hline & p90 & 0.28 & 0.18 & 0.13 & 0.09 & 0.08 & 0.06 & 0.05 & 0.05 & 0.05 & 0.04 & 0.03 & 0.04 & 0.04 & 0.06 \\
\hline & p95 & 0.28 & 0.18 & 0.13 & 0.09 & 0.08 & 0.08 & 0.05 & 0.05 & 0.05 & 0.04 & 0.03 & 0.04 & 0.04 & 0.06 \\
\hline & Max. & 0.28 & 0.22 & 0.17 & 0.14 & 0.12 & 0.1 & 0.09 & 0.09 & 0.08 & 0.07 & 0.06 & 0.07 & 0.06 & 0.07 \\
\hline & Mean & 0.28 & 0.22 & 0.17 & 0.14 & 0.12 & 0.1 & 0.09 & 0.09 & 0.08 & 0.07 & 0.06 & 0.07 & 0.06 & 0.07 \\
\hline & Median & 0.28 & 0.22 & 0.17 & 0.14 & 0.12 & 0.1 & 0.09 & 0.09 & 0.08 & 0.07 & 0.06 & 0.07 & 0.08 & 0.07 \\
\hline & p90 & 0.28 & 0.22 & 0.17 & 0.14 & 0.12 & 0.1 & 0.09 & 0.09 & 0.08 & 0.07 & 0.08 & 0.07 & 0.08 & 0.07 \\
\hline & p95 & 0.28 & 0.22 & 0.17 & 0.14 & 0.12 & 0.1 & 0.09 & 0.09 & 0.08 & 0.07 & 0.06 & 0.07 & 0.06 & 0.07 \\
\hline & Max. & 0.32 & 0.33 & 0.33 & 0.32 & 0.31 & 0.31 & 0.31 & 0.3 & 0.3 & 0.3 & 0.3 & 0.3 & 0.3 & 0.3 \\
\hline & Mean & 0.28 & 0.29 & 0.31 & 0.32 & 0.32 & 0.33 & 0.33 & 0.33 & 0.33 & 0.33 & 0.33 & 0.33 & 0.33 & 0.32 \\
\hline & Median & 0.24 & 0.27 & 0.29 & 0.31 & 0.32 & 0.33 & 0.34 & 0.34 & 0.35 & 0.35 & 0.38 & 0.38 & 0.38 & 0.35 \\
\hline & p90 & 0.27 & 0.29 & 0.29 & 0.3 & 0.3 & 0.31 & 0.31 & 0.32 & 0.32 & 0.34 & 0.34 & 0.35 & 0.35 & 0.35 \\
\hline & p95 & 0.29 & 0.3 & 0.3 & 0.3 & 0.3 & 0.3 & 0.3 & 0.31 & 0.31 & 0.32 & 0.33 & 0.33 & 0.33 & 0.33 \\
\hline & Max. & 0.14 & 0.19 & 0.21 & 0.21 & 0.22 & 0.23 & 0.24 & 0.24 & 0.25 & 0.29 & 0.32 & 0.32 & 0.39 & 0.38 \\
\hline & Mean & 0.19 & 0.24 & 0.25 & 0.24 & 0.24 & 0.25 & 0.28 & 0.27 & 0.3 & 0.38 & 0.39 & 0.42 & 0.47 & 0.49 \\
\hline & Median & 0.23 & 0.28 & 0.28 & 0.27 & 0.28 & 0.29 & 0.29 & 0.33 & 0.35 & 0.4 & 0.45 & 0.43 & 0.45 & 0.52 \\
\hline & p90 & 0.17 & 0.24 & 0.25 & 0.25 & 0.25 & 0.27 & 0.27 & 0.28 & 0.3 & 0.34 & 0.38 & 0.37 & 0.44 & 0.45 \\
\hline & p95 & 0.17 & 0.23 & 0.24 & 0.25 & 0.25 & 0.28 & 0.27 & 0.27 & 0.29 & 0.31 & 0.37 & 0.38 & 0.43 & 0.45 \\
\hline & Max. & 0.13 & 0.19 & 0.24 & 0.28 & 0.3 & 0.32 & 0.34 & 0.35 & 0.38 & 0.38 & 0.39 & 0.4 & 0.41 & 0.41 \\
\hline & Mean & 0.28 & 0.38 & 0.4 & 0.39 & 0.38 & 0.33 & 0.29 & 0.28 & 0.24 & 0.22 & 0.2 & 0.19 & 0.18 & 0.17 \\
\hline & Median & 0.32 & 0.43 & 0.45 & 0.43 & 0.38 & 0.34 & 0.28 & 0.25 & 0.21 & 0.18 & 0.15 & 0.15 & 0.13 & 0.12 \\
\hline & p90 & 0.18 & 0.24 & 0.29 & 0.32 & 0.34 & 0.35 & 0.35 & 0.34 & 0.34 & 0.34 & 0.34 & 0.33 & 0.33 & 0.32 \\
\hline & p95 & 0.14 & 0.22 & 0.27 & 0.3 & 0.32 & 0.34 & 0.35 & 0.35 & 0.35 & 0.38 & 0.38 & 0.38 & 0.38 & 0.36 \\
\hline & Max. & 0.28 & 0.17 & 0.12 & 0.1 & 0.1 & 0.1 & 0.1 & 0.12 & 0.11 & 0.14 & 0.14 & 0.15 & 0.14 & 0.16 \\
\hline & Mean & 0.27 & 0.18 & 0.13 & 0.12 & 0.12 & 0.13 & 0.14 & 0.15 & 0.16 & 0.19 & 0.2 & 0.21 & 0.2 & 0.2 \\
\hline CS & Median & 0.28 & 0.19 & 0.14 & 0.14 & 0.14 & 0.15 & 0.17 & 0.18 & 0.19 & 0.22 & 0.22 & 0.23 & 0.22 & 0.23 \\
\hline & p90 & 0.28 & 0.17 & 0.12 & 0.1 & 0.1 & 0.1 & 0.11 & 0.13 & 0.12 & 0.15 & 0.16 & 0.16 & 0.16 & 0.17 \\
\hline & p95 & 0.28 & 0.17 & 0.12 & 0.1 & 0.1 & 0.1 & 0.1 & 0.12 & 0.12 & 0.15 & 0.15 & 0.18 & 0.15 & 0.16 \\
\hline
\end{tabular}


434 In this research we analyzed how $\mathrm{L}_{\mathrm{FW}}$-derived metrics varied according to pulse density, voxel 435 size and assignation value. Key results indicate that $\mathrm{L}_{\mathrm{FW}}$-derived metric variations due to pulse 436 density differences can be modelled, and therefore their impact reduced by setting a MPD, 437 modifying the voxel size and/or the assignation value used. This may help to diminish the side438 lap effect in a particular study area, and therefore to obtain a more accurate estimate of forest 439 stand variables.

441 Results showed that $\mathrm{L}_{\mathrm{FW}}$-derived metric variations related to pulse density have a negative 442 exponential behavior, especially with small voxel sizes. Usually, there is a MPD from which 443 metric values are stabilized. In new LFW acquisitions, this MPD should be the minimum pulse 444 density value registered by the sensor to avoid the side-lap effect. However, the MPD is not 445 constant for every $\mathrm{L}_{\mathrm{FW}}$-derived metric, voxel size or assignation values employed. Therefore, in 446 practice, either the most affected LFw-derived metrics should be avoided for estimation of forest 447 stand variables, the voxel size increased or the assignation value modified.

449 On the other hand, when LFw has already been acquired, pulse density cannot be increased, and 450 therefore other strategies are required, such as modifying $\mathrm{L}_{\mathrm{FW}}$ parameters. Our results showed 451 that increasing the voxel size and/or modifying the assignation value can make more stable $\mathrm{L}_{\mathrm{FW}}-$ 452 derived metrics. The probability that larger voxels are crossed by at least one waveform is 453 higher, avoiding the gaps in the voxel columns that may alter $L_{F W}$-derived metric values. 454 Eventually, a trade-off between increasing voxel size to reduce side-lap effect and a substantial 455 loss of resolution should be considered. Regarding the assignation value, its effect on the 
456 stability of $\mathrm{L}_{\mathrm{FW}}$-derived metrics depends on the chosen metrics. Some standard $\mathrm{L}_{\mathrm{FW}}$-derived

457 metrics, such as RWE, have unstable behavior, whereas some others, such as WD, have not. In

458 general, the increment of the voxel size and the change of the assignation value reduce the $\mathrm{LFW}_{\mathrm{FW}}$

459 derived metric variation.

460

461 MPD values determine the minimum pulse density required to obtain stable $\mathrm{L}_{\mathrm{FW}}$-derived metrics.

462 However, the variation trend of some $\mathrm{L}_{\mathrm{FW}}$-derived metrics does not follow a negative

463 exponential model. Additionally, in some metrics (e.g. WD) higher values of MPD do not

464 correspond to higher values of TVar. Therefore, the introduction of TVar complements the MPD

465 as an indicator of the variability of the $\mathrm{L}_{\mathrm{FW}}$-derived metric due to pulse density changes.

466

467 Regarding different behavior among $\mathrm{LFW}_{\mathrm{FW}}$-derived metrics, NP and RWE are more sensitive to

468 pulse density changes than the rest. The lack of one or more voxel values means fewer peaks and

469 a different sum of amplitudes in the wave. On the contrary, HOME, WD, ROUGH (at lower

470 voxel sizes) and FS are less affected, since they are metrics that are related either to the height or

471 to the top texture of the canopy, where the laser energy from airborne sensors arrives without

472 occlusion (Crespo-Peremarch and Ruiz, 2017). WD only requires a proper estimation of the

473 height of the beginning of the waveform (top of the canopy), and it is well determined if the

474 waveform intersects with the top of the trees. HOME calculation involves the beginning of the

475 waveform as well as the height of the median energy. The latter is usually well registered, since

476 it often corresponds to the densest vertical layer (see HOME values in Fig. 3). ROUGH and FS

477 calculation requires the beginning of the waveform, and the position and amplitude of the first 
478 peak. Therefore, HOME, WD, ROUGH and FS vary if some voxel columns have no data due to

479 a low pulse density. In order to avoid this, an increment of the voxel size is required.

480 In addition, there is remarkable disparity in $\mathrm{LFW}_{\mathrm{FW}}$-derived metric values using different assignation

481 values. MPD and TVar values from WD do not vary, since the beginning of the waveform does

482 not vary by modifying the assignation value. HOME has slight differences, since the height of

483 the median energy may vary depending on the assignation employed. NP also presents minor

484 variation, since the pseudo-vertical waveform has more singularities when the maximum

485 assignation value is employed. ROUGH also has some differences due to possible variations of

486 the first peak. RWE is the most variable $\mathrm{L}_{\mathrm{FW}}$-derived metric. As it is computed as the sum of

487 amplitudes of a waveform, the sum of maximum values may substantially differ from the sum of

488 median values, for instance. A normalized metric may be used in order to avoid these

489 differences. A possible approach could be to calculate a normalized RWE (nRWE) following Eq.

490 (4), where $\mathrm{x}$ is equal to RWE, and $\min (\mathrm{x})$ and $\max (\mathrm{x})$ are the minimum and maximum RWE

491 values, respectively, for each assignation value. Thus, nRWE values from different assignation

492 values would be comparable. Finally, FS may present small differences, since the amplitude and

493 position of the first peak can vary as well.

494 To summarize, in order to reduce the side-lap effect in this scenario, the increment of the voxel

495 size is recommended for HOME, WD, FS, and RWE for the mean and median assignation 496 values, but not for ROUGH and RWE when maximum, percentiles 90 and 95 assignation values

497 are used. Besides, depending on the voxel size, the selection of the assignation value has to be 498 considered for RWE. According to results, NP might be discarded for estimating forest stand 499 variables because of its sensitivity to pulse density. Observing Figures 5 and 6, MPD, voxel size 500 and assignation values can be selected to minimize the side-lap effect in areas with similar 
501 vegetation types and densities. When planning a LiDAR flight, a MPD around 10 pulses $\mathrm{m}^{-2}, \mathrm{a}$ 502 voxel size of $0.75 \mathrm{~m}$ or similar, and the mean or median voxel assignation seem to optimize 503 general performance. This combination of parameters provides the minimum values of MPD for 504 most of the LFW-derived metrics (Fig. 5), except for NP. However, if LiDAR data are already 505 available and the pulse density cannot be increased, the maximum assignation and a voxel size of 506 about $0.75 \mathrm{~m}$ would be the most efficient option in terms of reduction of side-lap effect (Fig. 6). 507

508 There are few published studies that analyze how $\mathrm{L}_{\mathrm{FW}}$-derived metrics respond to progressive 509 variations of the LiDAR pulse density. Crespo-Peremarch et al. (2016) analyzed differences in

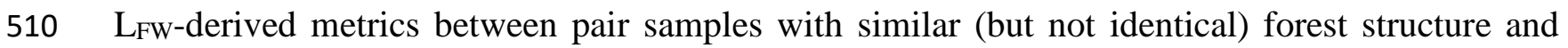
511 different pulse densities due to side-lap effect. They employed a paired Student's t-test and the 512 Wilcoxon signed-rank test to determine whether LFW-derived metrics were significantly different 513 between pair samples, quantifying these differences. Although general conclusions were reached 514 in this study, they do not allow for a practical treatment of the problem. Nevertheless, the 515 behavior of the metrics related to pulse density variations has been analyzed in more detail and 516 with greater sensitivity. For instance, the definition and use of MPD and TVar provides more 517 complete information about $\mathrm{L}_{\mathrm{FW}}$-derived metric variations, since they were measured in the same 518 sample but with different pulse density, as well as practical guidance to reduce the effect of 519 density differences in LFW data sets.

520 Our results are analogous to those of previous studies using $\mathrm{L}_{D}$. In these studies, a similar 521 tendency for $\mathrm{R}^{2}$ (Jakubowski et al., 2013; Manuri et al., 2017), reliability ratio (Magnussen et al., 522 2010; Hansen et al., 2015) and maximum height metric (Roussel et al., 2017) was found. These 523 values stabilize as pulse density increases. 
525 Modelling $\mathrm{L}_{\mathrm{FW}}$-derived metric variations related to the pulse density is relevant to remove or

526 reduce the side-lap effect when mapping metrics and forest structural variables are computed.

527 Depending on the LiDAR data acquisition step, different strategies can be followed. First, if LFW $_{F}$

528 data has not been acquired yet, a minimum pulse density that keeps LFw-derived metrics stable

529 may be set. Second, if $\mathrm{L}_{\mathrm{FW}}$ data has already been acquired, $\mathrm{L}_{\mathrm{FW}}$-derived metric variation can be

530 reduced by increasing the voxel size to a certain extent, and/or using a specific assignation value.

531 In this case, the pulse density cannot be increased, therefore $\mathrm{L}_{\mathrm{FW}}$ parameters that provide more

532 stable metrics should be used. Finally, if some variables do not respond to these strategies and

533 reducing the side-lap effect is not possible, then they should be avoided for further analyses.

\section{Conclusions}

536 The present study has analyzed the variation of $\mathrm{L}_{\mathrm{FW}}$-derived metrics according to the pulse

537 density. This variation is common due to side-lap areas that are registered with a higher pulse

538 density, and is known as "side-lap effect". Our results suggest that LFw-derived metric variations

539 related to pulse density can be modelled in most cases using a negative exponential model, and

540 therefore there is a threshold at which their values stabilize. From this point, a minimum pulse

541 density can be set to avoid the side-lap effect. In addition, modifying LFw parameters (i.e. voxel

542 size and assignation value) reduces the side-lap effect when pulse density cannot be increased, 543 e.g. when $\mathrm{L}_{\mathrm{FW}}$ data has already been acquired. Thus, an increment of the voxel size is 544 recommended for $\mathrm{HOME}, \mathrm{WD}, \mathrm{FS}$ and RWE for the mean and median assignation values. 545 Nevertheless, small voxel sizes make ROUGH and RWE for maximum, percentiles 90 and 95 546 more stable. On the other hand, the choice of the assignation value must be considered 
547 depending on the voxel size used for RWE. However, NP is sensitive to pulse density variations

548 and they cannot be reduced through $\mathrm{L}_{\mathrm{FW}}$ parameters, and therefore should be avoided for further

549 analyses. The results presented in this study have practical relevance in order to avoid the side-

550 lap effect when estimating forest stand variables using LFw data. Further studies could focus on

551 analyzing the effect of these parameters on different ecosystems with different dominant species,

552 as well as the effect of the emitted pulse energy and footprint size on LFW-derived metrics, since

553 they also influence the penetration of laser pulses.

554

\section{Acknowledgments}

556 This research has been funded by the Spanish Ministerio de Economía y Competitividad and 557 FEDER, in the framework of the project CGL2016-80705-R. The authors also thank the Bureau 558 of Land Management and the Panther Creek Remote Sensing and Research Cooperative Program 559 for the data provided.

560

561

\section{References}

562 Bailey, R.G., 1980. Description of the ecoregions of the United States. $2^{\text {nd }}$ edition USDA Forest 563 Service, Miscellaneous Publication 1391 (Washington, DC).

564

565 Bortolot, Z.J., Wynne, R.H., 2005. Estimating forest biomass using small footprint LiDAR data:

566 An individual tree-based approach that incorporates training data. ISPRS Journal of 
567 Photogrammetry and $\quad$ Remote $\quad$ Sensing. $\quad$ 59(6),

568 https://doi.org/10.1016/j.isprsjprs.2005.07.001

570 Cao, L., Coops, N.C., Hermosilla, T., Innes, J., Dai, J., She, G., 2014. Using small-footprint

571 discrete and full-waveform airborne LiDAR metrics to estimate total biomass and biomass

572 components in subtropical forests. Remote Sensing. 6(8), 7110-7135.

573 https://doi.org/10.3390/rs6087110

574

575 Cao, L., Coops, N.C., Innes, J.L., Dai, J., Ruan, H., She, G., 2016. Tree species classification in

576 subtropical forests using small-footprint full-waveform LiDAR data. International Journal of

577 Applied Earth Observation and Geoinformation. https://doi.org/10.1016/j.jag.2016.01.007

579 Crespo-Peremarch, P., Ruiz, L.A., Balaguer-Beser, A., Estornell, J., 2016. Analysis of the side580 lap effect on full-waveform LiDAR data acquisition for the estimation of forest structure 581 variables. ISPRS-International Archives of the Photogrammetry, Remote Sensing and Spatial 582 Information Sciences. 41, 603-610. https://doi.org/10.5194/isprs-archives-xli-b8-603-2016

584 Crespo-Peremarch, P., Ruiz, L.A., 2017. Análisis comparativo del potencial del ALS y TLS en la 585 caracterización estructural de la masa forestal basado en voxelización. XVII Congreso de la 586 Asociación Española de Teledetección, Nuevas plataformas y sensores de teledetección. 131587135. 
589 Crespo-Peremarch, P., Ruiz, L.A., 2018. Influence of lidar full-waveform density and voxel size 590 on forest stand estimates. IGARSS 2018 (International Geoscience and Remote Sensing 591 Symposium), Observing, Understanding and Forecasting the Dynamics of Our Planet.

593 David, M., 1977. Geostatistical ore reserve estimation, Elsevier, Amsterdam, The Netherlands. 594 https://doi.org/10.1016/c2009-0-14528-2

596 Duda, R.O., Hart, P.E., Stork, D.G., 2012. Pattern classification. John Wiley \& Sons.

598 Duong, V.H., 2010. Processing and application of ICESat large footprint full waveform laser 599 range data (Doctoral dissertation, TU Delft, Delft University of Technology).

600

601 Gobakken, T., Naesset, E., 2008. Assessing effects of laser point density, ground sampling 602 intensity, and field sample plot size on biophysical stand properties derived from airborne laser 603 scanner data. Canadian Journal of Forest Research. 38(5), 1095-1109. 604 https://doi.org/10.1139/x07-219 
606 González-Ferreiro, E., Diéguez-Aranda, U., Miranda, D., 2012. Estimation of stand variables in

607 Pinus radiata D. Don plantations using different LiDAR pulse densities. Forestry. 85(2), 281-

608 292. https://doi.org/10.1093/forestry/cps002

609

610 Guerra-Hernández, J., Tomé, M., González-Ferreiro, E., 2016. Using low density LiDAR data to 611 map Mediterranean forest characteristics by means of an area-based approach and height 612 threshold analysis. Revista de Teledetección. 0(46), 103-117. 613 https://doi.org/10.4995/raet.2016.3980

614

615 Guo, L., Chehata, N., Mallet, C., Boukir, S., 2011. Relevance of airborne lidar and multispectral 616 image data for urban scene classification using Random Forests. ISPRS Journal of 617 Photogrammetry and Semote Sensing. 66(1),

618 https://doi.org/10.1016/j.isprsjprs.2010.08.007

620 Hansen, E.H., Gobakken, T., Naesset, E., 2015. Effects of pulse density on digital terrain models 621 and canopy metrics using airborne laser scanning in a tropical rainforest. Remote Sensing. 7(7), 622 8453-8468. https://doi.org/10.3390/rs70708453

624 Harten, A., 1983. High resolution schemes for hyperbolic conservation laws. Journal of 625 Computational Physics. 49(3), 357-393. https://doi.org/10.1016/0021-9991(83)90136-5 
627 Heinzel, J., Koch, B., 2011. Exploiting full-waveform LiDAR parameters for tree species 628 classification. International Journal of Applied Earth Observation and Geoinformation. 13(1), 629 152-160. https://doi.org/10.1016/j.jag.2010.09.010

630

631 Hermosilla, T., Ruiz, L.A., Kazakova, A.N., Coops, N.C., Moskal, L.M., 2014a. Estimation of 632 forest structure and canopy fuel parameters from small-footprint full-waveform LiDAR data. 633 International Journal of Wildland Fire. 23(2), 224-233. https://doi.org/10.1071/wf13086

634

635 Hermosilla, T., Coops, N.C., Ruiz, L.A., Moskal, L.M., 2014b. Deriving pseudo-vertical 636 waveforms from small-footprint full-waveform LiDAR data. Remote Sensing Letters. 5(4), 332637 341. https://doi.org/10.1080/2150704x.2014.903350

639 Hevia, A., Álvarez-González, J., Ruiz-Fernández, E., Prendes, C., Ruiz-González, A., Majada, J., 640 González-Ferreiro, E., 2016. Modelling canopy fuel and forest stand variables and characterizing 641 the influence of thinning in the stand structure using airborne LiDAR. Revista de Teledetección. 642 0(45), 41-55. https://doi.org/10.4995/raet.20163979

643

644 Jakubowski, M.K., Guo, Q., Kelly, M., 2013. Tradeoffs between lidar pulse density and forest 645 measurement accuracy. Remote Sensing of Environment. 130, 245-253. 646 https://doi.org/10.1016/j.rse.2012.11.024

647 
648 Kashani, A.G., Olsen, M.J., Parrish, C.E., Wilson, N., 2015. A review of LiDAR radiometric

649 processing: From ad hoc intensity correction to rigorous radiometric calibration. Sensors. 15(11),

650 28099-28128. https://doi.org/10.3390/s151128099

651

652 Kukko, A., Kaasalainen, S., Litkey, P., 2008. Effect of incidence angle on laser scanner intensity 653 and surface data. Applied Optics. 47(7), 986-992. https://doi.org/10.1364/ao.47.000986

654

655 Lefsky, M.A., Harding, D.J., Keller, M., Cohen, W.B., Carabajal, C.C., Del Bom Espirito-Santo, 656 F., Hunter, M.O., de Oliveira Jr., R., 2005. Estimates of forest canopy height and aboveground 657 biomass using ICESat. Geophysical Research Letters. 32(22). 658 https://doi.org/10.1029/2005g1023971

659

660 Lim, K., Treitz, P., Wulder, M., St-Onge, B., Flood, M., 2003. LiDAR remote sensing of forest 661 structure. Progress in Physical Geography. 27(1), 88-106.

662

663 Magnussen, S., Naesset, E., Gobakken T., 2010. Reliability of LiDAR derived predictors of 664 forest inventory attributes: A case study with Norway spruce. Remote Sensing of Environment. 665 114(4), 700-712. https://doi.org/10.1016/j.rse.2009.11.007 
667 Mallet, C., Bretar, F., 2009. Full-waveform topographic lidar: State-of-the-art. ISPRS Journal of 668 Photogrammetry and Remote Sensing.

669 https://doi.org/10.1016/j.isprsjprs.2008.09.007

670

671 Manuri, S., Andersen, H.E., McGaughey, R.J., Brack, C., 2017. Assessing the influence of return

672 density on estimation of lidar-based aboveground biomass in tropical peat swamp forests of

673 Kalimantan, Indonesia. International Journal of Applied Earth Observation and Geoinformation.

674 56, 24-35. https://doi.org/10.1016/j.jag.2016.11.002

675

676 Mutlu, M., Popescu, S.C., Stripling, C., Spencer, T., 2008. Mapping surface fuel models using

677 lidar and multispectral data fusion for fire behavior. Remote Sensing of Environment. 112(1),

678 274-285. https://doi.org/10.1016/j.rse.2007.05.005

679

680 Reitberger, J., Krzystek, P., Stilla, U., 2008. Analysis of full waveform LiDAR data for the

681 classification of deciduous and coniferous trees. International Journal of Remote Sensing. 29(5),

682 1407-1431. https://doi.org/10.1080/01431160701736448

683

684 Reitberger, J., Schnörr, C., Krzystek, P., Stilla, U., 2009. 3D segmentation of single trees

685 exploiting full waveform LiDAR data. ISPRS Journal of Photogrammetry and Remote Sensing.

686 64(6), 561-574. https://doi.org/10.1016/j.isprsjprs.2009.04.002

687 
688 Roussel, J.R., Caspersen, J., Béland, M., Thomas, S., Achim, A., 2017. Removing bias from 689 LiDAR-based estimates of canopy height: accounting for the effects of pulse density and 690 footprint size. Remote Sensing of Environment. 198, 16. 691 https://doi.org/10.1016/j.rse.2017.05.032

693 Ruiz, L.A., Hermosilla, T., Mauro, F., Godino, M., 2014. Analysis of the influence of plot size 694 and LiDAR density on forest structure attribute estimates. Forests. 5(5), 936-951. 695 https://doi.org/10.3390/f5050936

696

697 Ruiz, L.A., Recio, J.A., Crespo-Peremarch, P., Sapena, M., 2018. An object-based approach for 698 mapping forest structural types based on low-density LiDAR and multispectral imagery. 699 Geocarto International. 33(5), 443-457. https://doi.org/10.1080/10106049.2016.1265595

701 Silva, C.A., Hudak, A.T., Klauberg, C., Vierling, L.A., Gonzalez-Benecke, C., Carvalho, 702 S.D.P.C., Rodriguez, L.C.E., Cardil, A., 2017. Combined effect of pulse density and grid cell 703 size on predicting and mapping aboveground carbon in fast-growing Eucalyptus forest plantation 704 using airborne LiDAR data. Carbon Balance and Management. 12(1), 13. 705 https://doi.org/10.1186/s13021-017-0082-0 
707 Song, J.H., Han, S.H., Yu, K.Y., Kim, Y.I., 2002. Assessing the possibility of land-cover 708 classification using lidar intensity data. International Archives of Photogrammetry Remote 709 Sensing and Spatial Information Sciences. 34(3/B), 259-262.

711 Strunk, J., Temesgen, H., Andersen, H.E., Flewelling, J.P., Madsen, L., 2012. Effects of lidar

712 pulse density and sample size on a model-assisted approach to estimate forest inventory 713 variables. Canadian Journal of Remote Sensing. 38(5), 644-654. https://doi.org/10.5589/m12-052

715 Treitz, P., Lim, K., Woods, M., Pitt, D., Nesbitt, D., Etheridge, D., 2012. LiDAR sampling 716 density for forest resource inventories in Ontario, Canada. Remote Sensing. 4(4), 830-848. 717 https://doi.org/10.3390/rs4040830

719 Varo-Martínez, M.Á., Navarro-Cerrillo, R.M., Hernández-Clemente, R., Duque-Lazo, J., 2017. 720 Semi-automated stand delineation in Mediterranean Pinus sylvestris plantations through 721 segmentation of LiDAR data: The influence of pulse density. International Journal of Applied 722 Earth Observation and Geoinformation. 56, 54-64. https://doi.org/10.1016/j.jag.2016.12.002

724 Wagner, W., 2010. Radiometric calibration of small-footprint full-waveform airborne laser 725 scanner measurements: Basic physical concepts. ISPRS Journal of Photogrammetry and Remote 726 Sensing. 65(6), 505-513. https://doi.org/10.1016/j.isprsjprs.2010.06.007 